\title{
Aerosol particle morphology of residential coal combustion smoke
}

\author{
Tafadzwa Makonese ${ }^{\star 1}$, Patricia Forbes ${ }^{2}$, Lorraine Mudau ${ }^{2}$ and Harold J. Annegarn ${ }^{1,3}$ \\ ${ }^{1}$ University of Johannesburg, Dept. of Geography, Environmental Management \& Energy Studies, \\ PO Box 524, Auckland Park 2006, Johannesburg, South Africa. taffywandi@gmail.com \\ ${ }^{2}$ Laboratory for Separation Science, Department of Chemistry, University of Pretoria, Pretoria, 0002. \\ ${ }^{3}$ Energy Institute, Cape Peninsula University of Technology, Cape Town
}

\begin{abstract}
A study carried out at the University of Pretoria characterised aerosol particle morphology of residential coal combustion smoke. The general approach in this study was on individual particle conglomerations because the radiative, environmental, and health effects of particles may depend on specific properties of individual particles rather than on the averaged bulk composition properties. A novel, miniature denuder system, developed and tested at the University of Pretoria, was used to capture particle emissions from the coal fires. The denuder consists of two silicone rubber traps (for gas phase semi-volatile organic compound monitoring) in series separated by a quartz fibre filter (for particle collection). The denuders were positioned $1 \mathrm{~m}$ away from the fire and were connected to pumps that sampled $\sim 5$ litres of air over a 10 min sampling interval. A JSM 5800LV Scanning Electron Microscope with a Thermo Scientific EDS was used to analyse the structure and morphology of different aerosol samples from the quartz fibre filters. Eight samples from the different fire lighting methods were selected for SEM analysis. The punched samples were sputter coated with gold for 15 minutes using a K550 Emitech Sputter Coater. Results show that apart from the fine and ultra-fine particles, coal smoke from domestic burning also contains aerosols greater than $5 \mu \mathrm{m}$ in diameter. Consequently, we describe the potential for generation of 'giant' carbonaceous soot conglomerates with outer diameters of 5 to $100 \mu \mathrm{m}$. However, the exact mechanism for formation of such large soot conglomerates remains to be determined. We also describe the presence of spherules and solid 'melted toffee' irregular surfaces. Circumstantial evidence is used to postulate and discuss the possible modes of formation in terms of condensation, and partial melting. This work provides a description of the modes of formation and transformation of conglomerates originating from low temperature $\left(<800^{\circ} \mathrm{C}\right)$ coal combustion.
\end{abstract}

\section{Keywords}

Particle morphology, coal combustion, conglomerates, particulate matter, soot, smoke

\section{Introduction}

In many developing countries, such as South Africa, China and India, coal is used as a primary source of energy for generation of electricity, industrialisation and enhancement of standard of living for the increasing populations [Makonese et al., 2014; Finkelman et al., 2007]. In South Africa, although the majority of coal is used for electricity generation, high levels of coal fuel is burned in self-fabricated and inefficient cooking devices resulting in elevated emissions of products of incomplete combustion, which are released into the immediate environment. Particulate matter emissions from coal combustion are receiving significant attention from regulatory authorities and environmental scientists because of their effects on health.

Scanning electron microscopy with energy-dispersive X-ray analysis (SEM/EDS) has proved to be a valuable tool for analysing single particles from combustion processes [Li et al., 2010]. The tool provides useful information on the morphology, elemental composition and particle density of aerosols and also gives us a better insight about the origin of particles that whether emitted from anthropogenic or natural processes [Pachauri et al., 2013:523].

In this paper we describe the potential for generation of 'giant' carbonaceous soot conglomerates with outer diameters of 5 to $100 \mu \mathrm{m}$. However, the exact mechanism for formation of such large soot conglomerates remains to be determined. We also describe the presence of spherules and solid 'melted toffee' irregular surfaces. Circumstantial evidence is used to postulate and discuss the possible modes of formation in terms of condensation, and partial melting. This work is vital to understanding the modes of formation and transformation of conglomerates originating from low temperature $\left(<800^{\circ} \mathrm{C}\right)$ coal combustion.

\section{Materials and methodology}

\section{Combustion devices}

Fires were made in representative artisan-manufactured braziers, commonly known as imbawulas, purchased from users in residential areas of Johannesburg (Figure 1). 


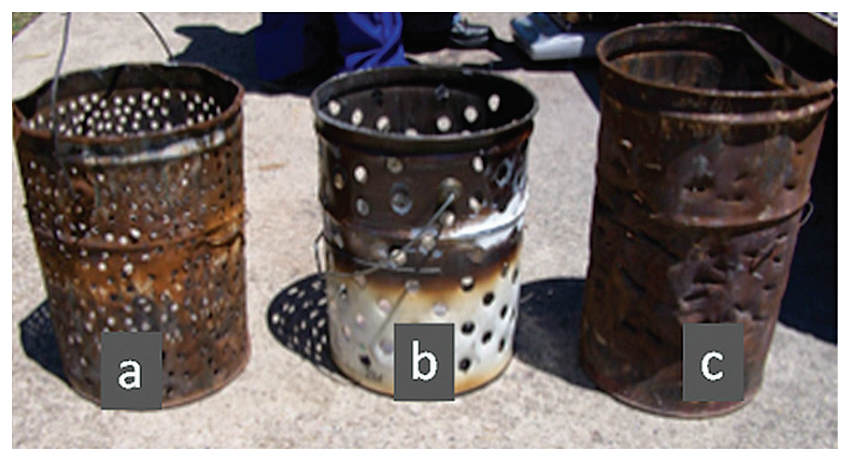

Figure 1: Illustration of imbawulas used in the experiment: (a) high ventilation case; (b) medium ventilation case; and (c) low ventilation case.

\section{Fuel analysis}

Experimental fuels were tested and analysed using appropriate standard methods at an independent laboratory. The fuel samples were analysed on an air dried basis. Results for the proximate and ultimate analysis for the coal grade used in this study are Table 1.

Table 1: Proximate and Ultimate analysis results of the D-grade type coal used in the study.

\begin{tabular}{|c|c|c|}
\hline $\begin{array}{l}\text { Parameter } \\
\text { (Air Dried Basis) }\end{array}$ & $\begin{array}{l}\text { Standard } \\
\text { Method }\end{array}$ & $\begin{array}{l}\text { Slater Coal } \\
\text { D-Grade }\end{array}$ \\
\hline $\begin{array}{l}\text { Moisture content (\%) } \\
\text { Volatiles (\%) } \\
\text { Ash (\%) } \\
\text { Fixed carbon (\%) } \\
\text { Calorific value (MJ/kg) } \\
\text { Calorific value (Kcal/kg) }\end{array}$ & $\begin{array}{l}\text { ISO } 5925 \\
\text { ISO } 562 \\
\text { ISO } 1171 \\
\text { By difference } \\
\text { ISO } 1928 \\
\text { ISO } 1928\end{array}$ & $\begin{array}{l}3.5 \\
20.3 \\
24.2 \\
52.0 \\
23.39 \\
5588\end{array}$ \\
\hline $\begin{array}{l}\text { Total sulphur (\%) } \\
\text { Carbon }(\%) \\
\text { Hydrogen }(\%) \\
\text { Nitrogen }(\%) \\
\text { Oxygen }(\%)\end{array}$ & $\begin{array}{l}\text { ASTM D4239 } \\
\text { ASTM D5373 } \\
\text { ASTM D5373 } \\
\text { ASTM D5373 } \\
\text { By difference }\end{array}$ & $\begin{array}{l}0.63 \\
62.56 \\
2.72 \\
1.43 \\
4.96\end{array}$ \\
\hline $\begin{array}{l}\text { Total Silica as } \mathrm{S}_{1} \mathrm{O}_{2}(\%) \\
\text { Aluminium as } \mathrm{Al}_{2} \mathrm{O}_{3}(\%) \\
\text { Total Iron as } \mathrm{Fe}_{2} \mathrm{O}_{3}(\%) \\
\text { Titanium as } \mathrm{TiO}_{2}(\%) \\
\text { Phosphorous as } \mathrm{P}_{2} \mathrm{O}_{5}(\%) \\
\text { Calcium as } \mathrm{CaO}(\%) \\
\text { Magnesium as } \mathrm{MgO}(\%) \\
\text { Sodium as } \mathrm{Na}_{2} \mathrm{O}(\%) \\
\text { Potassium as } \mathrm{K}_{2} \mathrm{O}(\%) \\
\text { Sulphur as } \mathrm{SO}_{3}(\%) \\
\text { Manganese as } \mathrm{MnO}_{2}(\%)\end{array}$ & $\begin{array}{l}\text { ASTM D4326 } \\
\text { ASTM D4326 } \\
\text { ASTM D4326 } \\
\text { ASTM D4326 } \\
\text { ASTM D4326 } \\
\text { ASTM D4326 } \\
\text { ASTM D4326 } \\
\text { ASTM D4326 } \\
\text { ASTM D4326 } \\
\text { ASTM D4326 } \\
\text { ASTM D4326 }\end{array}$ & $\begin{array}{l}58.6 \\
27.6 \\
6.63 \\
0.82 \\
0.55 \\
2.30 \\
0.83 \\
0.42 \\
0.79 \\
1.10 \\
0.12\end{array}$ \\
\hline
\end{tabular}

\section{Fire ignition method}

Two methods of lighting a coal fire in an imbawula stove namely the conventional/traditional method, and the Basa njengo Magogo (BnM) method, were compared in this study. The traditional way of lighting a coal fire entails laying the fire in the following order: paper, wood, ignition, after which coal is added at an appropriate time after the wood fire is established. In our experiments, $\sim 1000 \mathrm{~g}$ of coal were placed onto a grate at the bottom of the brazier followed by $36 \mathrm{~g}$ of rolled paper and $360 \mathrm{~g}$ of pine wood chips. After ignition, about $2000 \mathrm{~g}$ of coal was added on top of the already burning kindling.

In the BnM, the order of laying the fire is reversed - first coal, paper, and then wood, with a few lumps of coal added at an appropriate time after the fire has been lit. As such, $2000 \mathrm{~g}$ of coal was added to the bottom of the brazier onto a fuel grate followed by $36 \mathrm{~g}$ of paper and $360 \mathrm{~g}$ of kindling. After lighting the kindling, about $1000 \mathrm{~g}$ of coal was added to the brazier above the kindling.

\section{Filter preparation}

$6 \mathrm{~mm}$ quartz fibre filter punches were prepared and then placed in a vial to which methanol was added and swirled for one minute before being decanted. The same procedure was repeated with dichloromethane. The cleaned filter punches were then placed in an oven to dry for $30 \mathrm{~min}$ at $100^{\circ} \mathrm{C}$ and were then stored in a desiccator [Makonese et al., 2014]. The quartz filters are used to trap the particle phase emissions in the denuder configuration as shown in Figure 2.

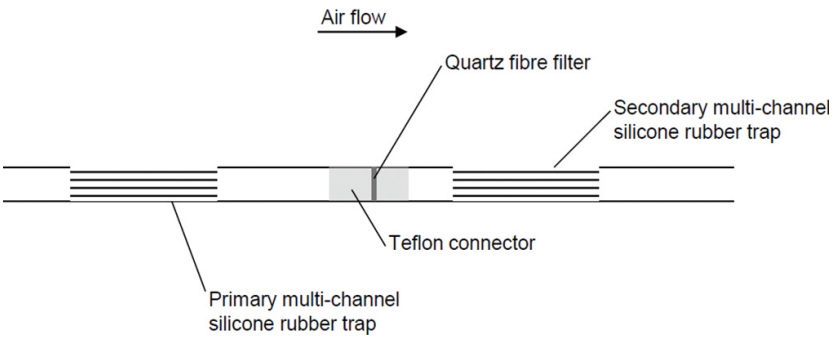

Figure 2: Schematic of the multi-channel silicone rubber traps and quartz fibre filter employed in the denuder configuration [Forbes et al., 2012].

\section{Experimental set-up}

In all fire lighting methods, sampling started about 2 min after ignition. The sampler location was $1 \mathrm{~m}$ from the combustion device, in the stream of effluent gases. Air samples were taken by means of a portable sampling pump at a flow rate of 0.5 L. min $^{-1}$ [Figure 3].

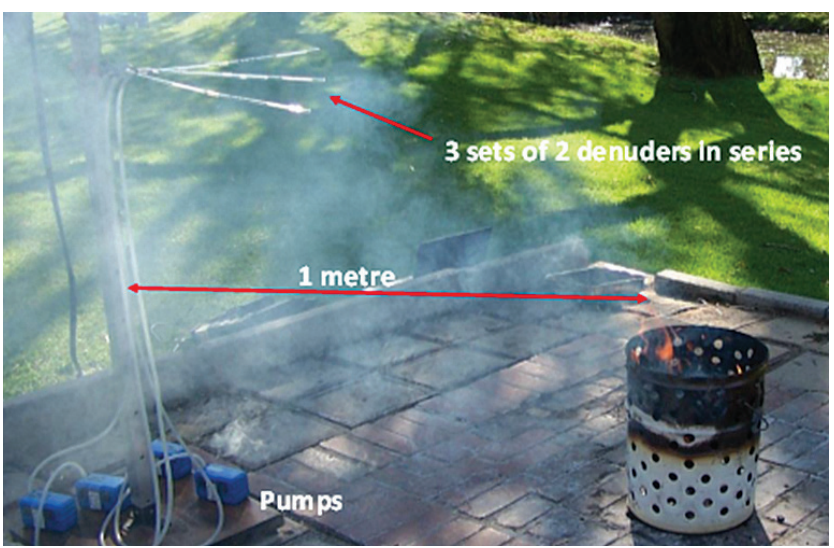

Figure 3: Experimental set-up for sampling particle emissions from imbawulas [Makonese et al., 2014].

Particle emissions were sampled for 10 min onto Quartz fibre filters, starting 2 min after ignition. These samples were taken in addition to gas phase samples with the denuders. Teflon tubing 
connections were used in each case to avoid contamination of the sample by leaching organics into the denuder system. After sampling, the traps were end-capped and wrapped in aluminium foil. Samples were then refrigerated prior to analysis.

\section{Analysis of quartz filters}

A JSM 5800LV Scanning Electron Microscope with a Thermo Scientific EDS was used to analyse the structure and morphology of different aerosol samples from the quartz fibre filters. Eight samples from the different fire lighting methods were selected for SEM analysis. The punched samples were sputter coated with gold for 15 minutes using a K550 Emitech Sputter Coater.

\section{Results and discussion}

\section{Identification of giant carbonaceous soot particles}

Figure 4 shows images from an aerosol filter from coal combustion in typical braziers as commonly used in real-world scenarios. Figure 4a shows a conglomerate with a "spongelike" structure similar to the one observed by Wentzel et al. [1999]. The dendritic form gives rise to a material with a high pore volume, and high specific surface. The individual branches of the conglomerate are typically up to $60 \mathrm{~nm}$ in width and consist of chains of spherules each smaller than $1 \mu \mathrm{m}$ in diameter. The low density of the giant aerosols makes them behave aerodynamically like most of the smaller spherical particles of unit density [Wentzel, 2000]. The presence of the giant carbonaceous conglomerates was observed on the filters from both the traditional and the Basa njengo Magogo lighting techniques. Major differences include: lower particle loading on the BnM filter, as expected from the lower visible smoke emissions seen at ignition. Typically the BnM conglomerates have a smaller mode diameter compared to conglomerates from the traditional lighting method.

Note on Figure $4 b$ the presence of a heavy loading of fuzzytextured conglomerates with diameters of $5 \mu \mathrm{m}$ or more. Like in the Wentzel et al. [1999] study, these giant particles are interspersed with a scattering of smaller particles either spherical or irregular in shape. Generally, soot particles are chain-like aggregates of carbon-bearing spheres. One soot aggregate may contain as many as hundreds of carbon spheres with typical diameters that range from 10 to $100 \mathrm{~nm}$, with some up to $150 \mathrm{~nm}$ [Li \& Shao, 2009]. The spherical primary particles which make up the soot particle are typically $80 \mathrm{~nm}$ in diameter, forming chain like agglomerates.

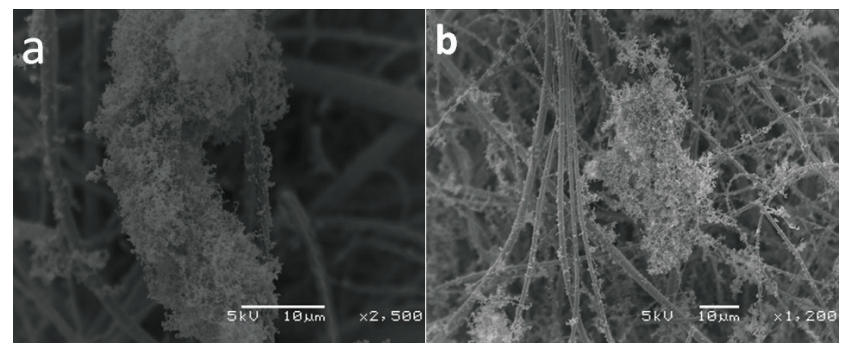

Figure 4: Micrographs of soot particles (a) and (b) from a high ventilation BnM imbawula fire.
The optical properties of these giant aerosol particles remain to be investigated. This however, falls outside the scope of this work and we recommend that further work be carried out in this regard. We have shown in this study that the origins of these giant particles are from domestic coal combustion in braziers. This assertion cements arguments put forward in Wentzel et al. [1999] that these conglomerates are likely to originate from coal combustion processes in the residential sector.

\section{Identification of spherules and "melted toffee" webs}

Figure 5 shows a carbon-dominated material forming an uneven film on the filter material. Such samples are not useful in characterizing single particles. However, they illustrate that the aerosols upon impaction with the filter were in a liquid form. The material then condensed around the quartz fibre material resulting in the formation of web-like conglomerates [Figure 5a]. At low aerosol concentrations and at high temperature (decay phase as shown in Wentzel, 2000), complete or partially solidified spherules can be found on the filters [Figure 5b]. The solidified spheres indicate that they do not arise on impaction with the filter, but that they already exist in the exhaust/flue or in the atmosphere before collection.

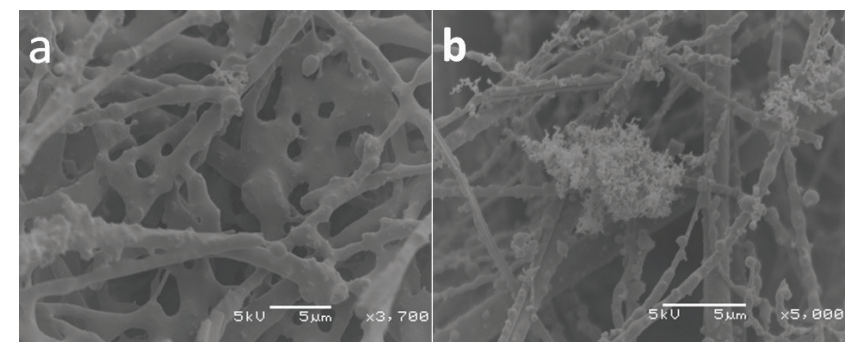

Figure 5: Showing condensation of particles and formation of spherical particles from (a) traditional fire lighting method at ignition and (b) BnM fire lighting method at ignition.

The traditional fire lighting method results in lower flame temperatures during the ignition phase compared to the Basa njengo Magogo method leading to high levels of smoke particles especially during the ignition phase. The lower temperatures coupled with the lack of oxygen needed for the complete combustion of the fuel results in high smoke emissions and other particles of incomplete combustion. This temperature difference results in differences in particle sizes and morphology emitted to the atmosphere from the two fire lighting methods. During low temperature ignition, the combustible components from the fuel are not completely burned, but condense on particles to form larger droplets which solidify upon cooling. Figure $5 b$ shows that at higher combustion temperatures the particulate emissions appears to be reduced, evidenced by a reduction in the formation of the amorphous (i.e. "melted toffee" like) mesh across overlapping fibres. Figure $5 b$ represents a somewhat pure form of condensation /diffusion growth, with minimal melting, compared to Figure 5a.

Figure 6 show that the liquid aerosol droplets from the coal fire form spherules and bead-like agglomerations along the length of the fibre material. The spherules do not arise on impaction 
with the filter, but are likely to be present in the exhaust before collection. The general shape of the individual spheroids is quite distinct. Clusters of spherules can be seen and resemble the thread-like basic structure of the giant carbonaceous particles. Such clusters illustrate fine particle growth through nucleation of nanometre size particles and diffusion aggregation toward a more stable mode of $0.3-0.5 \mu \mathrm{mad}$ [Wentzel et al., 1999].

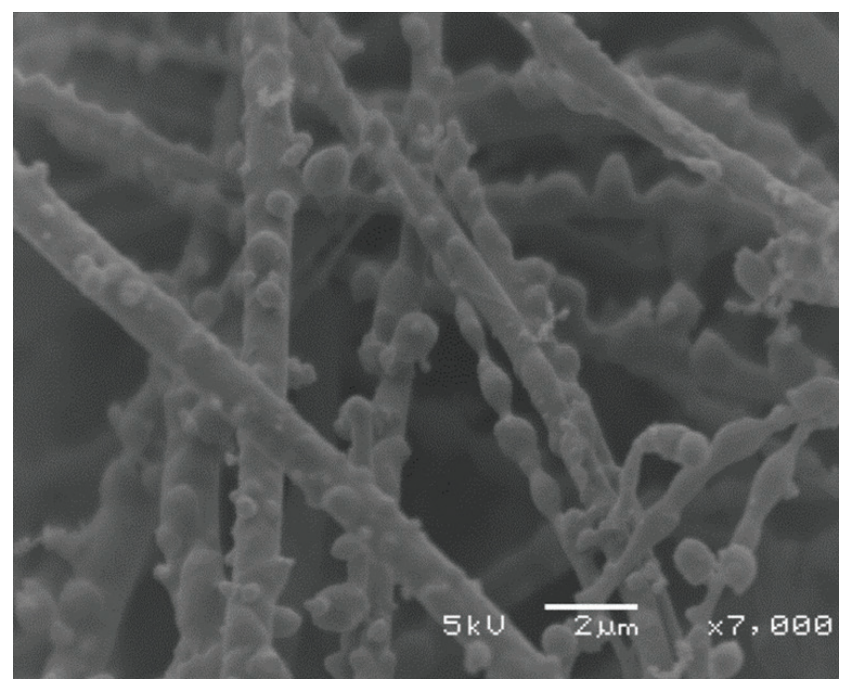

Figure 6: Details of bead-like particle agglomerates from a traditiona fire lighting method. The spherical particles are likely to be present in the exhaust or atmosphere as liquid aerosol droplets.

\section{Possible modes of formation}

In this section we consider some of the circumstantial evidence and postulate possible modes of formation of the large dendritic conglomerates. Unlike gas flames, soot in coal flames is thought to mostly evolve directly from the tar released from the coal during devolatilization. Soot formation is a very complicated process involving hundreds of elemental steps [Fletcher et al., 1997]. Qualitatively, there are three stages that lead to primary soot formation. According to Fletcher et al. [1997:291] the stages include (i) particle inception or nucleation; (ii) surface growth; and (iii) coagulation. After these three stages, however, the primary particles may continue to undergo (iv) agglomeration and (v) aggregation processes. During particle inception, the first condensed-phase material arises from the fuel molecules and their oxidation or pyrolysis products. Surface growth reactions lead to an increase in the mass of soot, but leave the number of particles unchanged. Coagulation also leads to particle growth, where particles collide and coalesce. Although the number of particles is decreased, the soot volume fraction remains constant during the coagulation process. At later stages in the growth process, particles no longer coalesce on collision, but are chemically fused together in chains. Primary particles are discernible in the chains. The growth by non-coalescent collision is known as agglomeration. Usually, agglomerates can sub-sequently become entangled with other agglo-merates through a process known as aggregation [Fletcher et al., 1997:292].

The morphology shown in Figure 6 suggests that the super- micron particles are primarily generated from the minerals in coal during combustion in the brazier. The formation mechanisms may involve coalescence of inherent minerals, fragmentation of chars, and the melting of excluded minerals [Wu et al., 2011; Linak et al., 2007]. However, the contribution of different mechanisms to the formation of super-micron particles during low temperature domestic combustion events is difficult to distinguish from the present results.

The coal type and fire-lighting methods would have an impact on aerosol formation and can highlight differences in the modes of formation of other soot types. The coals used in this study have relatively high fractions of volatile compounds. When employing the traditional method of lighting a coal fire, an oxygen depleted atmosphere is created in the brazier above the pyrolytic zone and the gradual heating of the brazier allows for the semi-volatile organic compounds to be released from the solid coal and, on cooling, condense. Especially during the initial ignition phase and immediately after refuelling, conditions would favour evaporation and re-condensation, rather than combustion, of volatile and semi-volatile fractions [Wentzel et al., 1999]. The growth into giant conglomerates is likely to occur in the high concentration zones of the stove, as once released into the atmosphere further growth through joining of conglomerates would be inhibited on account of their size and low diffusion velocities [Wentzel, 2000].

The decrease in soot yield with increasing temperature (i.e. high temperatures at ignition when employing the top-lit fire lighting method compared to the bottom up approach) can be explained by the stability of tar molecules at high temperatures and the reactions of tar with gaseous species existing in the post-flame region of the stove. Increases in temperature favour the 'cracking' reaction, which leads to a lower soot yield. Another reason for the decrease of soot with temperature may be due to reactions of the oxygen-containing species, especially $\mathrm{OH}$ and $\mathrm{O}$ radicals, with tar molecules and polycyclic aromatic hydrocarbons (PAHs). The concentrations of oxygen-containing radicals such as $\mathrm{OH}$ and $\mathrm{O}$ increase drastically with increases in temperature [Fletcher et al., 1997].

\section{Conclusion}

Results presented herein show that coal smoke from domestic burning comprises of aerosols of a range of sizes including those greater than $5 \mu \mathrm{m}$ in diameter. The experiments performed in this study have shown the potential for generation of large soot agglomerates (5-100 $\mu \mathrm{m}$ in diameter). However, the exact mechanism for formation of such large soot conglomerates remains to be determined. We have shown in this study that the origins of these giant particles are from domestic coal combustion in braziers. This assertion cements arguments put forward in Wentzel et al. [1999] that these conglomerates are likely to originate from coal combustion processes in the residential sector. However, based on the available evidence presented in this paper, it is not possible to establish modes of growth and transformation of the giant conglomerates. 
Results have also shown that the fire-lighting methods have an impact on aerosol formation and can highlight differences in the modes of formation of other soot types. A decrease in soot is noticed at higher ignition temperatures (typical of the $\mathrm{BnM}$ ). This shows that the BnM method of lighting a coal fire holds potential for reducing soot particle emissions to the immediate environment, especially during the ignition phase.

\section{Acknowledgements}

We thank the Microscopy Unit of the University of Pretoria, for use of the SEM; the University of Johannesburg for financial support through a URC/Faculty of Science grant to the SeTAR Centre; Thokozile Sithole (SeTAR Centre, University of Johannesburg) and Thapelo Chalatsi (University of Pretoria) for assisting with sampling; Daniel Masekameni (University of Johannesburg) for providing the braziers from his field surveys; Antoinette Buys (UP) for assisting with the SEM analyses. This study was supported in part from a grant from the Global Alliance for Clean Cookstoves (GACC) to the SeTAR Centre as a Regional Stove Testing and Development Centre.

\section{References}

Finkelman, B.R. 2007, 'Health impacts of coal: facts and fallacies', Ambio, 36 (1): 103 - 106

Fletcher T.H., Mat J., Rigby J.R., Brown A.L., Webb B.W. 1997, 'Soot in coal combustion systems', Prog. Energy Combust. Sci., 23:283-301.

Forbes P.B.C., Karg E.W., Zimmermann R., Rohwer E.R. 2012, 'The use of multi-channel silicone rubber traps as denuders for polycyclic aromatic hydrocarbons', Analytica Chimica Acta, 730:71-9.

Li W., Shao L.Y. 2009, 'Transmission electron microscopy study of aerosol particles from the brown hazes in Northern China', J. Geophys. Res. 114:D09302

Li W., Shao L.Y., Shen R., Wang Z., Yang S., Tang U. 2010, 'Size, composition and mixing state of individual aerosol particles in South China Coastal City', J. Environ. Sci. 22:561-69.

Linak W.P., Yoo J.-I., Wasson S.J., Zhu W., Wendt, J.O.L., Huggins F.E., Chen Y., Shah N., Huffman G.P., Gilmour M.I. 2007, 'Ultrafine ash aerosols from coal combustion: Characterization and health effects', Proceedings of the Combustion Institute, 31:1929-37.

Makonese T., Forbes P., Mudau L., Annegarn H.J. 2014, 'Monitoring of polycyclic aromatic hydrocarbon (PAH) emissions from real world uses of domestic coal braziers', Proceedings of the Domestic Use of Energy Conference, 31 March - 2 April 2014, Cape Peninsula University, Cape Town, South Africa.

Pachauri T., Singla V., Satsangi A., Lakhani A, Maharaj Kumari K. 2013, 'SEM-EDX charac-terization of individual coarse particles in Agra, India', Aerosol and Air Quality Research, 13:523-36.

Wentzel M. 2000. 'Characterization of aerosols from the South African township of Soweto', PhD thesis, Technische Hochschule Darmstadt, Germany.

Wentzel M., Annegarn H.J., Helas G., Weinbruch S., Balogh A.G., Sithole J.S. 1999, 'Giant dentritic carbonaceous particles in Soweto aerosols', South African Journal of Science, 95:141-5.

Wu H., Pedersen A.G., Glarborg P., Frandsen F.J., Dam-Johansen K., Sander B. 2011, 'Formation of fine particles in co-combustion of coal and solid recovered fuel in a pulverized coal-fired power station', Proceedings of the Combustion Institute, 33:2845-52. 